\title{
Influencing Factors of Health Care Expenditure for Rural Residents in China after Enforcing New Rural Cooperative Medical System
}

\author{
Ziyuan Deng \\ College of Economics and Management, Sichuan Agricultural University \\ Room 411,Unit 2, Building 6,Chengdu Campus of Sichuan Agricultural University \\ Huimin Rd.211, 611130, Wenjiang District, Chengdu, China \\ Tel: +86-155-2073-5255Ｅ-mail: 237344897@qq.com
}

Hua Guo

College of Economics and Management, Sichuan Agricultural University

Chengdu Campus of Sichuan Agricultural University,

Huimin Rd.211, 611130, Wenjiang District, Chengdu, China

Tel: +86-155-2073-599Ｅ-mail: huaguohua@sina.com

Yuansheng Jiang (Corresponding author)

College of Economics and Management, Sichuan Agricultural University

Tel: +86-28-8629-0883 E-mail:yjiang15@yahoo.com.cn

Received: October 25, $2011 \quad$ Accepted: November 16, $2011 \quad$ Published: January 5, 2011

doi:10.5430/ijfr.v3n1p95 URL: http://dx.doi.org/10.5430/ijfr.v3n1p95

This paper was supported by National Social Science Fund Project of China: The Research on NCMS under the Background of "the New Medical Reform" (Grant No.10XGL014)

\begin{abstract}
Based on the time series from 2004 to 2010, applying gray correlation analysis theory, this paper analyzes the influencing factors of health care expenditure of Chinese people in rural area after implementing the new Rural Cooperative Medical System. The result showed that, after enforcing new Rural Cooperative Medical System, the increase of rural residents' health care expenditure in china was still mainly driven by the improvement of farmers' income. The new Rural Cooperative Medical System has appeared effective, but compensatory mechanisms have yet to be perfect. And during this period of time, the increasing number of rural doctors and the price fluctuations of medical care have little effect on farmers' health spending.
\end{abstract}

Keywords: New Rural Cooperative Medical System, Rural Resident Health Care Expenditure, Influencing Factors, Gray Correlation Analysis Theory

\section{Introduction}

In recent years, the health care expenditure of rural residents in China has been increasing steadily. The health spending increased from 27.17 Yuan p.a in 1993 to 326 Yuan p.a in 2010, nearly 12 times' growth. And this has also been maintained in a steady growing rate (as shown in picture1). However, compared with urban residents, rural residents' medical treatment and health care expenditure is still in serious shortage. In 2008, the proportion of two-week prevalence rate of rural residents and city residents was $0.796: 1$, whlie the per capita health care expenditure of rural residents was only around $30 \%$ of urban residents. At the same time, the absolute amount of rural residents' health care expenditure was obviously insufficient. The data of the fourth National Health Service Survey (NHSS) showed that, in 2008 , the proportion of the rural residents who should receive medical treatment but haven't had it was $37.8 \%$, and the ratio of whom would be admitted to the hospital but didn't reached to $24.7 \%$.Therefore, it is undoubtedly significant, 
theoretically and practically meaningful in china to research the influencing factors of health care expenditure for rural residents under the background of implementing the new Rural Cooperative Medical System (NCMS)— the epochal reform of rural medical and health system.

Many scholars home and abroad have conducted multifaceted and multi-angle researches on the factors which influencing health care expenditure. Rosett (1973) analyzed influencing factors of the medical care expenditure using Labor Statistics of consumer spending data in the United States Bureau report. The effect of the coinsurance rate on the medical service expenditure was shown by Manning (1987), etc. The analysis of influencing factors to rural residents' health care expenditure in China focused mainly on family economical environment variables, family characteristics, medical service variables, and policy changes in the four categories of factors. Ping (2003)pointed that, in the market-oriented environment, health care expenditure was affected by the price and income, the two basic economic variables. Income is the most important factor of health care spending growth. Newhouse (1970) and Zhao (2001) both suggested that medical care expenditure income elasticity is greater than 1. But Ping (2003) found that the influencing factor is disparate in different places. In China, western farmers' medical decision significantly depended on the level of income, but this relation was not clear in the East. There are two quite different views about whether influence factor of medical price really existed. Fan (2001) showed that rural residents' health care expenditure growth is mainly due to the rise of medical price. However, Luo (2010) held the opinion that this effect wasn't obvious with panel data of 26 provinces in China. From the microscopic family factors, Lu (2010) proposed that educational level, family size, self-evaluation of health condition all had influence on medical care expenditure. What is notable is that Zhang (2010) pointed out that NCMS have gradually grown to be steady. That guided and stimulated farmers' medical consumption behavior to change as expected. However, Lv (2008) believed that institutional factors, such as NCMS haven't had significant impact on health care expenditure of rural residents.

In conclusion, the above study is mainly based on the farmer's level and macro level. So far, the NCMS in rural areas of China has been widely carried out. In 2010, the participation rate of new rural cooperative medical system reached $96 \%$, it raised 130.83 billion Yuan in funding but only spent 118.78 Yuan on expenses. However, the existing studies have not used time series and put NCMS as an influencing factor of rural health care expenditure to analyze it formally. At the same time, the influence of NCMS on the farmers' medical treatment and health care expenditure haven't yet reached a consistent conclusion. Therefore, this article will analyze the influencing factors of rural residents' health care expenditure by using the financing mechanism, compensation mechanism of NCMS, which are the two most important parts of it as variables, combine with income level and some other influencing factors.

\section{Research Methods, Selection of Variables and Data Sources}

\subsection{Research Methods}

Based on previous studies, there were a series of useful methods to study the factors on the health care expenditure in rural area. For example, panel data model, Tobit model, demand function and demand elasticity etc. But due to that the NCMS have only had 7 years of data available, since it began to be implemented a few ago. Considering the character of small amount of the data that can use to design the model, this article will adopt the method of gray correlation analysis, which we believe will be the most suitable way to analyze this issue. Grey relational analysis is widely used in the numerical relations between the various systems (or factors) of disciplines. Not affected by the quantity of sample and with the typical distribution or not, this method can be applied. Many researches applied this method, for example, science and technology investment effect on economic growth, industrial structure influence on energy consumption, the influence factors of real estate market demand.

\subsection{Selection of Variables}

Variables can be divided into internal variables and external variables. Internal variables based on Grossman's health demand theory, which study health as part of human capital that from the point of individual demand, and support that education level, income level affect the health service utilization. As mentioned above, income level, family characteristics, medical expenses, medical accessibility and availability, rural medical care system reform and other variables were used in previous research. But farmers' family characteristic variables, such as farmer education level, family size, self-evaluation of health condition are uncertain factors. At the same time, at the national level, family characteristics don't change obviously in a short period of time. However, the macro influencing factors can be changed by the government behavior and the policies. Therefore, this article selects the medical care price index, rural per capita net income, the per capita amount of financing of NCMS, the number of rural doctors, the per capita compensation of NCMS as variables to analyze influencing factors on per capita health care expenditure of rural residents. 


\subsection{Data Sources}

In this paper, the data are come from the previous China Statistical Yearbook and China Health Statistical Yearbook, but some part of data has been processed based on the original figures provided. The medical care price index for 2003 was set as fixed base year (fixed base year $=100$ ). The number of rural doctors is the sum of the number of county-level hospitals, township hospitals and village clinics. Relevant data was shown as table 1.

\section{Factors That Affect Rural Residents' Per Capita Health Care Expenditure Based on Grey Correlative Analysis}

The basic idea of Grey correlation analysis is to judge their relationship according to sequences' geometrical similarity degree. This degree between the corresponding sequences is larger when their curve is closer, Vice versa.

\subsection{The Computation of Grey Correlation Degree}

The gray correlation that between per capita health care expenditure of rural residents and the medical care price index , the per capita amount of financing of NCMS, rural per capita net income, the number of rural doctors, the per capita compensation of NCMS is calculated as follows:

Let X0 be the rural residents' per health care expenditure, $\mathrm{Xi}$ is the impact factors $(\mathrm{i}=1,2, \ldots)$. therefore: $\mathrm{X} 0=\{\mathrm{X} 0(\mathrm{k})$, $\mathrm{k}=1,2, \ldots \ldots 6\} ; \mathrm{Xi}=\{\mathrm{Xi}(\mathrm{k}), \mathrm{k}=1,2, \ldots \ldots 6\}$, and $\mathrm{k}$ is the number of year samples, $\mathrm{i}(\mathrm{i}=1,2,3,4,5)$ is the influencing factors.

(1) the dimensionless processing to every column of data: $\mathrm{X}_{\mathrm{i}}=\frac{x_{i}(k)}{x_{i}(1)}(\mathrm{i}=0,1, \ldots \ldots 6)$.

$x_{0}^{\prime}=(1,1.287,1.466,1.609,1.884,2.201,2.496)$

$x_{1}^{\prime}=(1,0.985,0.982,1.002,1.032,1.046,1.075)$

$x_{2}^{\prime}=(1,0.961,1.190,1.345,2.199,2,589,3,576)$

$x_{3}^{\prime}=(1,1.108,1.222,1.410,1.621,1.755,2.016)$

$x_{4}^{\prime}=(1,1.013,1.007,1.008,1.042,1.091,1.107)$

$x_{5}^{\prime}=(1,1.046,1.152,1.447,2.462,3.357,4.305)$

(2) Calculating the difference sequence: $\Delta \mathrm{i}(\mathrm{k})=\left|x_{i}^{\prime}(k)-x_{0}^{\prime}(k)\right|$

$\mid x_{1}^{\prime}-x_{0}^{\prime}$
$x_{2}^{\prime}-x_{0}^{\prime}=(0,0.301,0.484,0.607,0.851,1.155,1.421)$
$x_{3}^{\prime}-x_{0}^{\prime} \mid=(0,0.326,0.277,0.264,0.316,0.387,1.080)$
$x_{4}^{\prime}-x_{0}^{\prime} \mid=(0,0.274,0.459,0.602,0.842,1.110,1.389)$
$x_{5}^{\prime}-x_{0}^{\prime} \mid=(0,0.241,0.315,0.163,0.578,1.156,1.809)$

(3) Set the distinguishing coefficient is 0.5 , and calculating the correlation coefficient:

$$
\xi_{i}(k)=\frac{\min _{i} \min _{k}\left|x_{0}(k)-x_{i}(k)\right|+0.5 \max _{i} \max _{k}\left|x_{0}(k)-x_{i}(k)\right|}{\left|x_{0}(k)-x_{i}(k)\right|+0.5 \max _{i} \max _{k}\left|x_{0}(k)-x_{i}(k)\right|}
$$

$\xi(k)=\quad\left(\begin{array}{ccccccc}1 & 0.749 & 0.650 & 0.597 & 0.514 & 0.438 & 0.388 \\ 1 & 0.734 & 0.765 & 0.773 & 0.740 & 0.699 & 0.455 \\ 1 & 0.834 & 0.786 & 0.819 & 0.774 & 0.668 & 0.652 \\ 1 & 0.767 & 0.662 & 0.599 & 0.517 & 0.448 & 0.393 \\ 1 & 0.789 & 0.741 & 0.847 & 0.609 & 0.438 & 0.332\end{array}\right)$

(4) Calculation of correlation degree:

$$
\begin{aligned}
r_{i} & =\frac{1}{N} \sum_{k=1}^{N} \xi_{i}(k) \\
r_{i} & =(0.619,0.738,0.791,0.627,0.679)
\end{aligned}
$$

\subsection{Estimation Results}

Based on the above calculations, the degree of correlation between per capita health care expenditure of rural residents and the related parameters of variable is shown in table 2. 
As is shown in table 2, the correlation order of variable is $\mathrm{r} 3>\mathrm{r} 2>\mathrm{r} 5>\mathrm{r} 4>\mathrm{r} 1$. In the rural area, the most related degree for health care expenditure is rural per capita net income, which is 0.791 . This shows that the development of income in rural area is most close to the increase of rural medical care consumption. The higher the income, the stronger the willing to spend money on sickness.

The correlation degree between the per capita amount of financing of NCMS and per capita health care expenditure of rural residents is 0.738 . And the degree for the per capita compensation of NCMS is 0.679 . Both of them are relatively high. This suggests that the establishment and development of NCMS in the period has played a larger role in promoting health care expenditure of rural residents increase. Specifically, the degree of the per capita amount of financing of NCMS is high which reflects the governmental support in rural health care have close relationship in rural residents' health care expenditure, but the promoting effect of the per capita compensation of NCMS is lower than the per capita amount of financing. At the same time, the correlation of NCMS lower than that of the per capita annual net income of farmers shows that the effect of NCMS on rural residents' health care spending lower than that of economic income.

The correlation degree between the number of rural doctors and per capita health care expenditure of rural residents is relatively small, which is 0.627 . This indicator reflects the effect of developing rural medical and health service level to rural medical care consumption isn't relatively obvious. The associated degree that the medical care price index and per capita health care expenditure of rural residents is minimum, which is 0.619 . That shows during this period, the change of medical care price have less effect on health care consumption of rural residents. The price factor is no longer the key influence factor to rural residents when they exist needs and wishes.

\section{Discussion}

From the estimated results, after the implementation of NCMS, the growth of health care expenditure for rural residents in china was mainly driven by the improvement of their income. The establishment and implementation of NCMS has improved the rural medical care consumption. The increase of rural doctors and fluctuation of medical price have little effect on farmers' health spending.

This conclusion is generally consistent with previous research results. There is no doubt that income level affect expenditure, especially in medical care expenditure of rural residents. The influencing factor of medical price is relatively weak. This is the same as the research of Luo (2010), while contradicted with the research of Fan (2001). The reason for this difference is that the research was in different periods. After the implementation of NCMS, the influence of price factor weakened, which is no longer the key influence factor. The implementation of NCMS has contributed to soaring of health care expenditure of rural residents. This is agreed with Zhang (2010) whose research was that the NCMS has guided and stimulated the expected change of rural medical consumption. So, the NCMS has indeed promoted rural health investment. But it is worth to note that the NCMS, as a social insurance, should ensure the farmer, whether poor or rich, will be able to get the corresponding medical service. However, at present, income level is still the most important factor that affecting health care spending. This suggests that the role of NCMS has not been effectively. The mechanism of NCMS, especially the compensation mechanism still needs further perfection.

Based on the above research conclusion, there are some suggestions as follow:

(1) combine the rural residents' own efforts with government's lead, and raise farmer' income level. Farmer should actively seek the way of economical development. In addition, the government should actively guide farmer to increase income. Such as establishing a reasonable rural industry development plan; enhancing the degree of organization of farmers; improving the rural infrastructure construction and perfecting relevant management system.

(2) Government should continue to increase the investment ratio in the rural medical and health aspects, especially for NCMS. WHO recommended health users pay $30 \%$, and the government pays $70 \%$ as the long-term goal of medical compensation. The proportion of spending on health care by the central government, local government, and the rural resident should be 2: 2: 1 . However, the current level in China is far behind this level. Therefore, the government still needs to further increase the investment for rural health.

(3) The mechanisms of NCMS should be actively improved. It is important to perfect the financing mechanism and compensation mechanism of NCMS, which will ensure farmer's basic medical and health rights, and reduce the situation that rural residents who should have treatment but couldn't, who should be admitted to the hospital but didn't At the same time, fund management and supervision mechanism of NCMS also need to be clear.

(4) Improving the rural medical service. Nowadays, the government should actively guide farmer to establish and improve rural three tier health network, that is medical care - disease prevention-health service, which can improve rural medical service level. This will effectively solve the problem of difficulty in receiving medical service, and promote rural health level. 


\section{References}

Hua Fan.(2001). The Economical Analysis: the Shortage of Rural Residents' Health Investigation. China Rural Survey. $6,37-43$.

Yonghui Zhang. Zhengbing Wang.(2007). The Obstacles and Policy Suggestions: Health Care System Reform in Rural China. Journal of Northwest A\&F University (Social Science Edition). 6, 13 - 17.

Yanhong Luo, Lei Ding.(2010). The Empirical Analysis of Urban and Rural Residents Health Care Expenditure in China Based on the Panel Data of 26 Provinces. Chinese Journal of Health Statistics. 2, $118-121$.

Xinpu Lu, Ming Wu.(2010). The Influencing Factors That Effect Floating Population on Family Medical Expenditure in Beijing City—Based on Tobit Model. Journal of Peking University (Health Sciences). 5, 565 - 569.

Xinqiao Ping.(2003). The Selection of Financing Mechanism of Rural Health Care Based on the View of Farmer's Medical and Health Care Expenditure in China. Management World.11, $52-62$.

Yuxin Zhao.(2001). The Report of Total Health Expense, China, 1999. Chinese Health Economics. 9, 9- 13.

Yimin Zhang, Xueshan Feng.(2010). Health Expenditure Analysis for Urban and Rural Residents in China. Chinese Journal of Hospital Administration. 3, $185-188$.

Yan Lv, Manqi Ke.( 2008). The Influencing Factors: Rural Residents' Health Care Expenditure in China. Northern Economy. 6, $18-19$.

Hongxia Bi, Xingli Xue.( 2011). The Financial Aid Problems of NCMS: Policy Evaluation, Grant Demand and Financial Optimization. Issues in Agricultural Economy. 1, 66 - 72.

Newhouse JP.(1970). Toward a Theory of Nonprofit Institution:An Economic Model of a Hospital.American Economic Review. 60(1), 64-74.

Grossman M.(1972).The Demand for Health:a Theoretical and Empirical Investigation.New York:Columbia University Press,( Chapter 1).

Richard N. Rosett, Lien - fu Huang. (1973). The Effect of Health Insurance on the Demand for Medical Care. The Journal of Political Economy. 2, 281-305.

Table 1. The relevant data of per health care expenditure for rural residents in china, 2004-2010

\begin{tabular}{|c|c|c|c|c|c|c|c|}
\hline year & 2004 & 2005 & 2006 & 2007 & 2008 & 2009 & 2010 \\
\hline Rural residents' per health care expenditure (yuan)(Y) & 130.6 & 168.1 & 191.5 & 210.2 & 246 & 287.5 & 326 \\
\hline The medical care price index $(\mathrm{X} 1)$ & 97.9 & 96.48 & 96.14 & 98.11 & 101.06 & 102.42 & 105.22 \\
\hline $\begin{array}{l}\text { The per capita amount of financing of NCMS } \\
\qquad(\text { yuan })(\mathrm{X} 2)\end{array}$ & 43.79 & 42.1 & 52.1 & 58.9 & 96.3 & 113.36 & 156.6 \\
\hline Rural per capita net income (yuan) (X3) & 2936.4 & 3254.9 & 3587 & 4140.4 & 4760.6 & 5153.2 & 5919 \\
\hline The number of rural doctors (Ten thousand)(X4) & 113.95 & 115.45 & 114.83 & 114.79 & 118.69 & 124.36 & 126.12 \\
\hline The per capita compensation of NCMS (yuan)(X5) & 33 & 34.53 & 38 & 47.74 & 81.23 & 110.79 & 142.07 \\
\hline
\end{tabular}

Data sources: China Health Statistical Yearbook (2004-2010); China Statistical Yearbook (2005 - 2010).

Note. The medical care price index of year 2010 is average value of 12 months. 
Table 2. The degree of correlation

\begin{tabular}{|c|c|c|c|c|c|}
\hline Variable & $\begin{array}{c}\text { The medical } \\
\text { care price } \\
\text { index(X1) }\end{array}$ & $\begin{array}{c}\text { The per capita } \\
\text { amount of financing } \\
\text { of NCMS } \\
\text { (yuan)(X2) }\end{array}$ & $\begin{array}{c}\text { Rural per } \\
\text { capita net } \\
\text { income } \\
\text { (yuan) (X3) }\end{array}$ & $\begin{array}{c}\text { The number of rural } \\
\text { doctors (Ten } \\
\text { thousand)(X4) }\end{array}$ & $\begin{array}{c}\text { The per capita } \\
\text { compensation of } \\
\text { NCMS (yuan)(X5) }\end{array}$ \\
\hline $\begin{array}{c}\text { The degree } \\
\text { of correlation }\end{array}$ & 0.619 & 0.738 & 0.791 & 0.627 & 0.679 \\
\hline
\end{tabular}

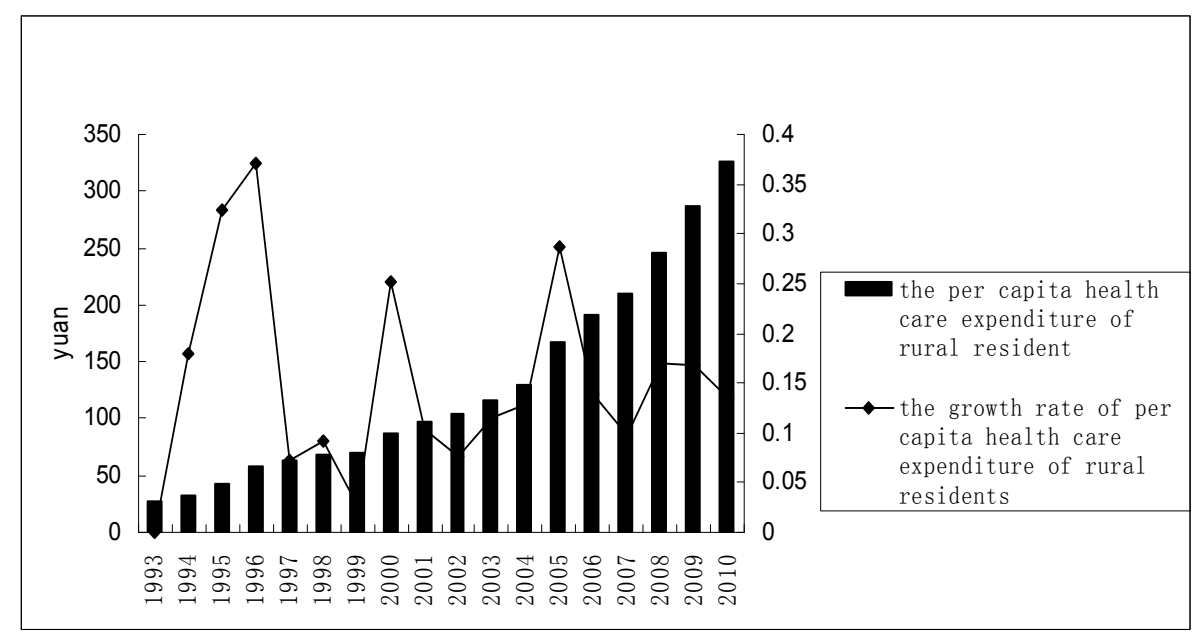

Figure 1. The Per Capita Health Care Expenditure and Its Growth Rate of Rural Residents in China, 1993-2010 Data sources: Statistical Yearbook of China. 